\title{
Towards a comprehensive global approach to prevention and control of NCDs
}

\author{
Martin McKee $^{1 *}$, Andy Haines ${ }^{2}$, Shah Ebrahim ${ }^{3}$, Peter Lamptey ${ }^{3}$, Mauricio L Barreto ${ }^{4}$, Don Matheson ${ }^{5}$, \\ Helen L Walls ${ }^{3,6,7}$, Sunia Foliaki ${ }^{5}$, J Jaime Miranda ${ }^{8}$, Oyun Chimeddamba ${ }^{9}$, Luis Garcia-Marcos ${ }^{10}$, Paolo Vineis ${ }^{11}$ \\ and Neil Pearce ${ }^{3,6}$
}

\begin{abstract}
Background: The " $25 \times 25$ " strategy to tackle the global challenge of non-communicable diseases takes a traditional approach, concentrating on a few diseases and their immediate risk factors.

Discussion: We propose elements of a comprehensive strategy to address NCDs that takes account of the evolving social, economic, environmental and health care contexts, while developing mechanisms to respond effectively to local patterns of disease. Principles that underpin the comprehensive strategy include: (a) a balance between measures that address health at the individual and population level; (b) the need to identify evidence-based feasible and effective approaches tailored to low and middle income countries rather than exporting questionable strategies developed in high income countries; (c) developing primary health care as a universal framework to support prevention and treatment; (d) ensuring the ability to respond in real time to the complex adaptive behaviours of the global food, tobacco, alcohol and transport industries; (e) integrating evidence-based, cost-effective, and affordable approaches within the post-2015 sustainable development agenda; ( $f$ ) determination of a set of priorities based on the NCD burden within each country, taking account of what it can afford, including the level of available development assistance; and (g) change from a universal "one-size fits all" approach of relatively simple prevention oriented approaches to more comprehensive multi-sectoral and development-oriented approaches which address both health systems and the determinants of NCD risk factors.
\end{abstract}

Summary: The $25 \times 25$ is approach is absolutely necessary but insufficient to tackle the the NCD disease burden of mortality and morbidity. A more comprehensive approach is recommended.

Keywords: Non-communicable diseases, Prevention, Health systems

\section{Background}

In 2011 world leaders met at the United Nations (UN) to state their commitment to "to address the prevention and control of non-communicable diseases worldwide" [1]. The World Health Organization, as the UN's specialised agency for health, subsequently published its Global NCD Action Plan 2013-2020 [2,3]. This proposes a series of voluntary targets to tackle the emerging global epidemic of NonCommunicable Diseases (NCDs) [4,5], with the goal of achieving a $25 \%$ relative reduction in mortality from four conditions (cardiovascular disease, cancer, diabetes and

\footnotetext{
* Correspondence: martin.mckee@lshtm.ac.uk

${ }^{1}$ European Centre on Health of Societies in Transition (ECOHOST), London

School of Hygiene and Tropical Medicine, London WC1H 9SH, UK

Full list of author information is available at the end of the article
}

chronic respiratory diseases) by 2025 [6]. The targets to achieve this " $25 \times 25$ " strategy [7] include reducing mortality from these four conditions and halting the rise in diabetes and obesity, by reducing alcohol consumption, increasing physical activity, reducing dietary salt and smoking, improving blood pressure control, and enhancing treatment of those at risk from or suffering from the major NCDs [8]. Yet, as we have argued elsewhere, these responses, which might be considered the 'standard' model, are modest given the scale of the challenge [9]. They will be insufficient to respond to the global forces driving the epidemics of NCDs, in particular the tobacco, alcohol and food industries, they are limited to four main NCDs which together account for only $54 \%$ of NCD DALYS, and they pay insufficient attention to the non-traditional risk factors, such as

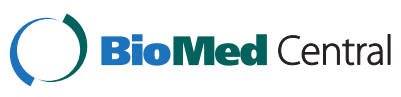

(c) 2014 McKee et al.; licensee BioMed Central Ltd. This is an Open Access article distributed under the terms of the Creative Commons Attribution License (http://creativecommons.org/licenses/by/4.0), which permits unrestricted use, distribution, and reproduction in any medium, provided the original work is properly credited. The Creative Commons Public Domain Dedication waiver (http://creativecommons.org/publicdomain/zero/1.0/) applies to the data made available in this article, unless otherwise stated. 
air pollution, and the need to strengthen health systems. In this paper we argue for the need to go beyond this standard model and discuss seven key issues that a more comprehensive approach should consider.

\section{Discussion}

\section{Balancing collective and individual responses}

A comprehensive strategy should include an appropriate balance of actions to prevent disease acting at the individual and the collective and the local and the global levels. All are important; there will always be a need for individual-level interventions, especially for those at high risk or with established disease, while there are some determinants of disease, such as air pollution and inadequate water supply that can only be tackled by collective action. However, interventions at the population level often achieve much greater benefits at lower cost. Similarly, policies must be tailored to local contexts while tackling shared regional or global threats.

The need for balance between the individual and the collective can be illustrated with tobacco-attributable disease [10]. At an individual level, existing smokers can be helped with individual or group behavioural interventions. Yet the main drivers of both smoking initiation and cessation lie at the population level, related to price, availability and marketing. Thus, increases in cigarette prices are effective in reducing smoking, [11] including in low- and middle-income countries [12]. Bans of pointof-sale displays reduce perceived availability [13] and bans on advertising in print media, radio and television serve to de-normalise the act of smoking [14]. This is further encouraged by removal of the one place where advertising is still permitted in many countries, the packs themselves, with emerging data from Australia on how standardised packaging reduces the attractiveness of smoking to young people [15]. The population-level interventions are either cost neutral or, in the case of tax rises, revenue raising, while individual approaches always incur costs associated with their delivery. The same principles apply to reducing hazardous consumption of alcohol and certain food products. Thus, density of alcohol [16] outlets is an important determinant of consumption while increases in alcohol prices reduce hazardous consumption [17]. It is, however, important to note that those selling these products will always argue against legislation and in favour of voluntary agreements [18], precisely because the latter are known to be less effective unless they incorporate clear targets and robust independent monitoring, which is rarely the case [19].

Collective measures often require action against "structural factors" or the "causes of the causes" [20] of disease. These will require measures in areas as diverse as tax and welfare, housing, transport, industry and agriculture, sometimes brought together under the heading of "Health in all Policies" [21]. This demands understanding of the complex and interrelated network of economic, environmental, social, commercial, and cultural determinants involved in health and the need for a range of integrated actions involving all parts of government and not just health ministries [22]. Although some actions to tackle these determinants can be taken at the local or national level, many will require concerted international responses.

Developing effective collective responses will be challenging as, in many countries, and especially where governance is weak and transparency limited, health ministries are the weakest within government and face opposition from powerful vested interests with close links to other stronger ministries and are often excluded from international discussions on key areas such as trade.

\section{What works where?}

The elements of a comprehensive strategy should be appropriate to the settings in which they are applied. As noted in the WHO Action Plan [2], it cannot be assumed that technologies or policies developed in highincome settings, where much of the evidence comes from, can simply be transferred to low and middle-income countries (LMIC), where the burden of disease is rising rapidly. These approaches will often require unaffordable levels of funding, skilled workers who do not exist, managerial systems that are already struggling, and distribution systems unable to ensure regular supplies of essential medicines [23]. Moreover, transfer of policies must also take account of cultural norms. Thus, in many countries in Asia, attempts to control hypertension must consider traditional belief systems, such as those found in India, China, and South East Asia, whereby "dis-ease" is equated with pain and feeling ill and there is limited recognition of the importance of treating an asymptomatic risk factor [24]. It must also take account of affordability of both treatment and the means of obtaining it (such as transport costs), in countries where even a miniscule charge may be unaffordable to families already trapped in a cycle of debt [25].

Nor can it be assumed that policies developed in one LMIC setting can be transferred to another at a similar level of development, given the need to take account of differences in implementation capacity, shared understanding of goals among those making and those implementing policies and, sometimes corruption [26]. The experience of scaling up HIV/AIDS services highlights the problems that arise when applying costing data derived in one setting to another where local data are lacking [27].

There is an extensive literature on international lesson learning and policy transfer [28] and approaches such as "theory driven evaluation" [29] or "realist evaluation" [30] go beyond the question whether something works but rather to understand circumstances that make it 
work properly. Although these approaches are used increasingly in health policy research [31], many healthrelated initiatives still ignore the context in which they are to be applied.

For these reasons, it is essential to build a portfolio of evidence on the cultural appropriateness, cost effectiveness, and equity implications in different settings, based on the creation of a culture of evaluation that runs through the policy process, from generating locally relevant evidence to translating it into formats that can be used by policy makers, drawing especially on the emerging body of evidence on knowledge translation in low and middle income countries [32].

\section{Strong primary health care}

As noted in the WHO Action Plan [2], action against NCDS should build on a foundation of strong primary care. In 1978, in Alma Ata, 134 countries committed to primary health care, defined as "the first level of contact of individuals, the family and community with the national health system bringing health care as close as possible to where people live and work, and constituting the first element of a continuing health care process" [33]. However, in over three decades since then, few health systems have lived up to that commitment. Instead, often encouraged by donors, many have invested in vertical health programmes, targeting individual conditions, with AIDS, tuberculosis, malaria, and more recently maternal health attracting particular attention. Yet research on health systems in countries at all levels of development shows that integrated primary health care provides more effective care and at lower cost than more fragmented systems [34] and countries that have adopted primary health care achieve better health outcomes [35-37].

The common risk factors for NCDs increase the probability of multiple disorders. Poor diet increases the risk of risk of diabetes, cardiovascular disease and some cancers, while smoking increases the risk of chronic obstructive pulmonary disease, cardiovascular disease, and many cancers. Moreover, risk factors often cluster within populations, disproportionately affecting those living in deprived circumstances [38]. There is also an increasing recognition of the growing rates of multi-morbidity in ageing populations, including not just the four diseases mentioned in the $25 \times 25$ strategy but also a wide range of conditions such as mental illness and neurological and musculo-skeletal diseases [39]. Crucially, many patients with chronic infectious disease, such as tuberculosis or HIV/AIDS, have co-existent NCDs [40,41]. There is little point in treating one condition but leaving the patient with the consequences of several others.

An effective response must involve the provision of integrated health services, as close to the population as possible, with no financial barriers to access. Yet this is often far from reality. For example, people with type I diabetes in many LMIC die because of lack of insulin [42]. In a 2003 study from Mozambique it was estimated that a child with type 1 diabetes could expect to live 3.8 years in Maputo, the capital, but only 7 months in rural areas [43]. Hypertension is also poorly controlled in many countries, with one recent study finding that only 12.7 of those with hypertension are aware of it, have received treatment, and achieved control, [44], leading to much avoidable death and disability. These challenges can only be addressed by a strong primary care system that can identify and treat those in need in a timely manner and, where necessary, refer them for more specialised care.

\section{Emerging threats}

The $25 \times 25$ strategy addresses the traditional risk factors, but not the underlying drivers of them. Just as mosquitoes are the vectors of the micro-organisms causing some devastating communicable diseases, it is now recognised that major corporations spread the traditional risk factors for NCDS [45]. Trade liberalisation, itself a major goal of these corporations that can exert a powerful influence on international regulations, is associated with increases in a range of NCDs [46]. These corporations can move extremely quickly, as seen when onceclosed economies, such as countries emerging from the USSR in the 1990s [47] and more recently, Myanmar, open to the world. They exploit any regulatory gaps, for example by placing brand imagery on consumer goods (brand stretching) or using social media to circumvent advertising bans. The major tobacco companies have exploited the opportunities presented by electronic cigarettes to reposition themselves as partners with governments in the fight against tobacco, while using the ability to advertise these new products to promote imagery that glamorises smoking [48]. Unfortunately, legislative processes are often very slow, and are slowed even further by corporate pressure, as with the European Union's revision of the Tobacco Products Directive [49]. Consequently, there is a strong case for a global horizon scanning function, identifying tactics used to promote unhealthy products, coupled with support for rapid legislative responses, such as a repository for existing legislation that can be adapted by other countries [50]. The alternative is that corporations will write the legislation, as happened when the tobacco industry assisted former Soviet countries with tax codes that, unsurprisingly, were the most favourable for their products. Effective action cannot ignore the political roots of global health, including what Kickbusch has termed the "commercial determinants of health" [51], demanding effective global governance based on commitments to global solidarity and shared responsibility [52]. 


\section{The post-2015 agenda}

The global response to NCDs should not stand in isolation from other international processes. The post-2015 development agenda represents an important opportunity to integrate efforts to reduce the burden of NCDs and promote sustainable development [3]. The recent identification of NCDs as a major threat to the global economy [53,54] provides a lever for moving NCDs from a peripheral to a central concern of global development. It now seems likely that Universal Health Coverage will feature prominently in the post-2015 development agenda [55]. On 12 December 2012 it was endorsed unequivocally by the UN General Assembly (including the United States), which resolved that it confirmed the "intrinsic role of health in achieving international sustainable development goals" [56]. Universal Health Coverage has been defined by the WHO as "access to key promotive, preventive, curative and rehabilitative health interventions for all at an affordable cost....", subject to the proviso that the cost of care "...[should] not put people at risk of financial catastrophe" [57]. Making it a reality will require the implementation of evidence-based, cost-effective, and affordable approaches that can reduce the burden of NCDs and promote sustainable development $[3,58]$.

The driving forces behind important risk factors for NCDs, such as fine particulate air pollution, physical inactivity and unhealthy diets, are linked to current patterns of unsustainable development, including the combustion of fossil fuels which results in climate change [58]. Indicators for the post 2015 development agenda must therefore link health and sustainability, addressing sectors such as energy, transport, housing, food and agriculture [59] as well as reflecting progress towards Universal Health Coverage. However, current proposals fall far short of what is needed [60].

\section{Matching priorities to resources}

An effective strategy must take account of the challenges that each country faces and its access to resources. Each country is at a different stage in the epidemiological transition. Its burden of NCDs is influenced by the demographic composition of its population, its exposure to risk factors, its stage in the nutritional and epidemiological transitions, its geography and its ability to provide effective health care [61]. For example, smoking-related disease may be less in some countries because of cultural barriers to smoking and limited penetration by tobacco corporations. While the debate about the role of thrifty genotypes and phenotypes remains unresolved [62], it is clear that some populations are much more susceptible to diabetes than others. In many countries, diet continues to be influenced heavily by traditional patterns of agriculture, even if this is rapidly changing. Moreover, these differences are seen not only among countries but within them, with substantial regional differences in large countries such as Brazil, India, or China, and between rural and urban areas almost everywhere, with the NCD epidemic progressing most rapidly in the latter.

Each country also has differing levels of available resources, whether raised domestically or from development assistance. Consequently, it will be essential that strategies to tackle NCDs are matched to both the resources available and the burden of disease, while not forgetting the need to ensure equity. There is a critical need to strengthen capacity in health ministries, which often have a much lower status and priority than other ministries, such as trade and defence. This will require a comprehensive package of measures to recruit, develop and retain skilled analysts and policy experts, supported by access to information about both their own country and the international literature on effective interventions. This, in turn, will require new tools for surveillance of NCDs and their risk factors, so far, these have been largely missing from surveys such as the Demographic and Health Surveys that have concentrated on maternal and child health and, more recently, HIV, as well as a culture of evaluation of new policies and interventions. There is also a need for investment in capacity to analyse the increased volume of data at sub-national level so that national 'norms' do not lose sight of concentrations of disease, need and equity issues in particular settings.

At the same time as national capacity and capability is built, there needs to be increased support for sub national health system development in districts and cities. The front line of the organised response has been shattered from decades of vertical programs. The NCD agenda can add to this fragmentation, or alternatively take a comprehensive systems approach.

\section{Progressive implementation of the $25 \times 25$ agenda}

As the WHO Action Plan notes [2], countries responding to the $25 \times 25$ agenda are starting from different points. Some have almost no capacity to prevent and treat NCDs, especially those emerging from conflict, while others have some capacity, often concentrated in urban centres that may function relatively well. Thus, a universal "one-size fits all" approach will not be appropriate. Countries also vary greatly in the extent to which they have moved from a fragmented model that, at best, responds to immediate demand to one that takes a broader view, employing an integrated strategy that addresses the range of risk factors, at both individual and collective level, and all steps along the trajectory from disease detection to treatment, control, and palliative care. Where resources, both in terms of money, trained workers, and systems of governance are limited, it will be necessary to start with interventions that 
can be delivered at scale within resource constraints. Models of health care can be developed that involve midlevel health workers, aided by simplified guidelines, and with access to essential medicines. However, while the starting points may differ, the end point should not. The $25 \times 25$ agenda sits alongside a number of other commitments and policies. These include the International Covenant on Economic, Social and Cultural Rights, which established the commitment to progressive realisation of the right to health by each state "to the maximum of its available resources" [63] and the post-2015 agenda. The most recent document (July 2014) from the Open Working Group on the Sustainable Development Goals proposes a target to "by 2030 reduce by one-third premature mortality from non-communicable diseases (NCDs) through prevention and treatment [64]...".

Thus, while countries will have to take account of available resources, there should be a clear vision of where they want to be and what can be achieved as resources increase, leading ultimately to more comprehensive, multi-faceted, multi-sectoral and development-oriented approaches integrating health and sustainability.

\section{Summary}

In this paper we argue for the need to go beyond the 'standard model' of preventing NCDs, focussing only on four risk factors (plus essential medicines for people at high risk of CVD) and four diseases. We do not offer a fully-developed strategy; rather, we argue that such a strategy is needed and highlights some key features that it should contain. These include: a) balancing collective and individual responses in ways that protect health at the individual level and view health as a common good; b) identifying effective approaches tailored to LMICs rather than exporting questionable strategies developed in HICs; c) strengthening health systems to support prevention and treatment efforts, with an emphasis on primary health care; d) creating the ability to react in real time to emerging threats, such as the complex adaptive behaviours of the global food, tobacco, alcohol and transport industries; e) adopting measures that promote sustainable development, thereby advancing the post2015 agenda; f) supporting prioritisation processes within health systems that respond to the local disease burden, what the country can afford, and the level of development assistance, and that are informed by but not overridden by global priorities; g) change from a universal "one-size fits all" approach to a progression from relatively simpler, public health oriented and affordable approaches to more complex, multi-sectoral and development oriented approaches. If these issues are taken into account, the chances of success may be considerably improved.

\section{Competing interests}

The authors declare that they have no competing interests.

\section{Authors' contributions}

All authors contributed to development of the ideas set out in the paper. MM and NP prepared the first draft, which all authors subsequently revised. All authors read and approved the final manuscript.

\section{Acknowledgements}

The Centre for Global NCDs is supported by the Wellcome Trust Institutional Strategic Support Fund, 097834/Z/11/B. The Centre for Public Health Research is supported by a Programme Grant from the Health Research Council of New Zealand. HLW was supported by an NHMRC Sidney Sax Public Health Fellowship (APP1037460) from the National Health and Medical Research Council of Australia. The CRONICAS Centre of Excellence in Chronic Diseases at Universidad Peruana Cayetano Heredia was funded with Federal funds from the United States National Heart, Lung and Blood Institute, National Institutes of Health, Department of Health and Human Services, under Contract No. HHSN268200900033C. None of these funders played any role in study design; in the collection, analysis, and interpretation of data; in the writing of the manuscript; or in the decision to submit the manuscript for publication.

\section{Author details}

${ }^{1}$ European Centre on Health of Societies in Transition (ECOHOST), London School of Hygiene and Tropical Medicine, London WC1H 9SH, UK. ${ }^{2}$ Departments of Social and Environmental Health Research and of Global Health and Development, London School of Hygiene and Tropical Medicine, London, UK. ${ }^{3}$ Centre for Global NCDs, London School of Hygiene and Tropical Medicine, London, UK. ${ }^{4}$ Instituto de Saude Coletiva, Federal University of Bahia, Bahia, Brazil. ${ }^{5}$ Centre for Public Health Research, Massey University, Wellington, New Zealand. 'everhulme Centre for Integrative Research on Agriculture and Health, London, UK. ${ }^{7}$ National Centre for Epidemiology and Population Health, The Australian National University, Canberra, Australia. ${ }^{8}$ CRONICAS Centre of Excellence in Chronic Diseases, and School of Medicine, Universidad Peruana Cayetano Heredia, Lima, Peru. ${ }^{9}$ Department of Epidemiology and Preventive Medicine, School of Public Health and Preventive Medicine (SPHPM), Monash University, Melbourne, Australia. ${ }^{10}$ Respiratory and Allergy Units, Arrixaca University Children's Hospital, University of Murcia and IMIB-Arrixaca Research Institute, Murcia, Spain. ${ }^{11}$ MRC-PHE Center for Environment and Health, School of Public Health, Imperial College, London, UK.

Received: 26 August 2014 Accepted: 15 October 2014 Published online: 28 October 2014

\section{References}

1. United Nations General Assembly: Political Declaration of the High-Level Meeting of the General Assembly on the Prevention and Control of NonCommunicable Diseases. A/66/L.1. New York: United Nations; 2011.

2. WHO: WHO Global NCD Action Plan 2013-2020. Geneva: WHO; 2013.

3. Alleyne G, Binagwaho A, Jahan S, Nugent R, Rojhani A, Stuckler D: Embedding non-communicable diseases in the post-2015 development agenda. The Lancet 2013, 381:566-574.

4. United Nations: High level meeting of the General Assembly on the Prevention \& Control of Non-communicable Diseases. New York: UN; 2011.

5. Beaglehole R, Bonita R, Alleyne G, Horton R, Li L, Lincoln P, Mbanya JC, McKee M, Moodie R, Nishtar S, Piot P, Reddy KS, Stuckler D, Lancet NCD Action Group: UN High-Level Meeting on Non-Communicable Diseases: addressing four questions. Lancet 2011, 378(9789):449-455.

6. World Health Organization: 66th World Health Assembly: Second Report of Committee A. Geneva: WHO; 2013.

7. Beaglehole R, Bonita R, Horton R, Ezzati M, Bhala N, Amuyunzu-Nyamongo M, Mwatsama M, Reddy KS: Measuring progress on NCDs: one goal and five targets. Lancet 2012, 380(9850):1283-1285.

8. WHO: Follow-up to the Political Declaration of the High-level Meeting of the General Assembly on the Prevention and Control of Non-communicable Diseases. Sixty sixth World Health Assembly Agenda item 13.1. Geneva: WHO; 2013.

9. Pearce N, Ebrahim S, McKee M, Lamptey P, Barreto ML, Matheson D, Walls H, Foliaki S, Miranda J, Chimeddamba O, Marcos LG, Haines A, Vineis P: 
The road to $25 \times 25$ : how can the five-target strategy reach its goal? Lancet Global Health 2014, 2:e126-e128.

10. Rosen L, Rosenberg E, McKee M, Gan-Noy S, Levin D, Mayshar E, Shacham G, Borowski J, Nun GB, Lev B, Healthy Israel 2020 Tobacco Control Subcommittee: A framework for developing an evidence-based, comprehensive tobacco control program. Health Res Policy Syst 2010, 8:17.

11. Wilson N, Thomson G: Tobacco tax as a health protecting policy: a brief review of the New Zealand evidence. N Z Med J 2005, 118(1213):U1403.

12. Kostova D, Tesche J, Perucic AM, Yurekli A, Asma S, GATS Collaborative Group: Exploring the relationship between cigarette prices and smoking among adults: a cross-country study of low- and middle-income nations. Nicotine Tob Res 2014, 16(Suppl 1):S10-5.

13. Kim AE, Nonnemaker JM, Loomis BR, Shafer PR, Shaikh A, Hill E, Holloway JW, Farrelly MC: Influence of point-of-sale tobacco displays and graphic health warning signs on adults: evidence from a virtual store experimental study. Am J Public Health 2014, 104(5):888-95.

14. Pierce JP, White VM, Emery SL: What public health strategies are needed to reduce smoking initiation? Tob Control 2012, 21(2):258-64.

15. Brose LS, Chong CB, Aspinall E, Michie S, McEwen A: Effects of standardised cigarette packaging on craving, motivation to stop and perceptions of cigarettes and packs. Psychol Health 2014 , 29(7):849-60.

16. Bryden A, Roberts B, McKee M, Petticrew M: A systematic review of the influence on alcohol use of community level availability and marketing of alcohol. Health Place 2012, 18(2):349-57.

17. Purshouse RC, Meier PS, Brennan A, Taylor KB, Rafia R: Estimated effect of alcohol pricing policies on health and health economic outcomes in England: an epidemiological model. Lancet 2010, 375(9723):1355-64.

18. Jacoby E, Rivera J, Cordera S, Gomes F, Garnier L, Castillo C, Reyes M: Legislation. Children. Obesity. Standing up for children's rights in Latin America. World Nutrition 2012, 11:483-516.

19. Bryden A, Petticrew M, Mays N, Eastmure E, Knai C: Voluntary agreements between government and business - a scoping review of the literature with specific reference to the Public Health Responsibility Deal. Health Policy 2013, 110(2-3):186-97.

20. Marmot M: Fair Society Healthy Lives. London: University College London; 2010.

21. Ståhl T, Wismar M, Ollila E, Lahtinen E, Leppo K: Health in all Policies: Prospects and Potentials. Helsinki: Ministry of Social Affairs and Health; 2006.

22. Chappell MJ, Wittman H, Bacon CM, Ferguson BG, Barrios LG, Barrios RG, Jaffee D, Lima J, Méndez VE, Morales H, Soto-Pinto L, Vandermeer J, Perfecto I: Food sovereignty: an alternative paradigm for poverty reduction and biodiversity conservation in Latin America. F1000Res 2013, 2:235.

23. Beran D, Abdraimova A, Akkazieva B, McKee M, Balabanova D, Yudkin JS: Diabetes in Kyrgyzstan: changes between 2002 and 2009. Int J Health Plann Manage 2013, 28(2):e121-37.

24. Xiong X, Yang X, Liu W, Chu F, Wang P, Wang J: Trends in the treatment of hypertension from the perspective of traditional chinese medicine. Evid Based Complement Alternat Med 2013, 2013:275279.

25. Xu K, Evans DB, Kawabata K, Zeramdini R, Klavus J, Murray CJ: Household catastrophic health expenditure: a multicountry analysis. Lancet 2003, 362(9378):111-7.

26. Lahariya C, Mishra A, Nandan D, Gautam P, Gupta S: Additional cash incentive within a conditional cash transfer scheme: a 'controlled before and during' design evaluation study from India. Indian J Public Health 2011, 55(2):115-20.

27. Beck EJ, Avila C, Gerbase S, Harling G, De Lay P: Counting the cost of not costing HIV health facilities accurately: pay now, or pay more later. Pharmacoeconomics 2012, 30(10):887-902.

28. Stone D: Learning Lessons, Policy Transfer and the International Diffusion of Policy Ideas. Warwick: University of Warwick. Centre for the Study of Globalisation and Regionalisation; 2001.

29. Chen H-T: Theory-driven Evaluations. London: Sage; 1990.

30. Pawson R: The Science of Evaluation: A Realist Manifesto. London: SAGE; 2013.

31. Balabanova D, Mills A, Conteh L, Akkazieva B, Banteyerga H, Dash U, Gilson L, Harmer A, Ibraimova A, Islam Z, Kidanu A, Koehlmoos TP, Limwattananon S, Muraleedharan VR, Murzalieva G, Palafox B, Panichkriangkrai W, Patcharanarumol W, Penn-Kekana L, Powell-Jackson T, Tangcharoensathien $\checkmark$, McKee M: Good health at low cost 25 years on: lessons for the future of health systems strengthening. Lancet 2013, 381(9883):2118-33.
32. Woelk G, Daniels K, Cliff J, Lewin S, Sevene E, Fernandes B, Mariano A, Matinhure S, Oxman AD, Lavis JN, Lundborg CS: Translating research into policy: lessons learned from eclampsia treatment and malaria control in three southern African countries. Health Res Policy Syst 2009, 7:31.

33. WHO: Declaration of Alma-Ata. Alma Ata: WHO \& UNICEF; 1978.

34. Starfield B, Shi L, Macinko J: Contribution of primary care to health systems and health. Milbank Q 2005, 83(3):457-502.

35. Starfield B, Shi L: Policy relevant determinants of health: an international perspective. Health Policy 2002, 60(3):201-18.

36. Hsieh VC, Wu JC, Wu TN, Chiang TL. Universal Coverage for Primary Health Care Is a Wise Investment: Evidence From 102 Low- and Middle-Income Countries. Asia Pac J Public Health 2013; doi:10.1177/ 1010539513492562.

37. Rasella D, Harhay MO, Pamponet ML, Aquino R, Barreto ML: Impact of primary health care on mortality from heart and cerebrovascular diseases in Brazil: a nationwide analysis of longitudinal data. BMJ 2014, 349:94014.

38. Ahmed, S.M., Hadi A, Razzaque A, Ashraf A, Juvekar S, Ng N, Kanungsukkasem U, Soonthornthada K, Van Minh H, Huu Bich T: Clustering of chronic non-communicable disease risk factors among selected Asian populations: levels and determinants. Glob Health Action 2009. 2. doi:10.3402/gha.v2i0.1986

39. Barnett K, Mercer SW, Norbury M, Watt G, Wyke S, Guthrie B: Epidemiology of multimorbidity and implications for health care, research, and medical education: a cross-sectional study. Lancet 2012, 380(9836):37-43.

40. Diez-Canseco F, Ipince A, Toyama M, Benate-Galvez Y, Galán-Rodas E, Medina-Verástegui JC, Sánchez-Moreno D, Araya R, Miranda JJ: Integration of mental health and chronic non-communicable diseases in Peru: challenges and opportunities for primary care settings. Rev Peru Med Exp Salud Publica 2014, 31(1):131-6.

41. Van Zyl Smit RN, Pai M, Yew WW, Leung CC, Zumla A, Bateman ED, Dheda $\mathrm{K}$ : Global lung health: the colliding epidemics of tuberculosis, tobacco smoking HIV and COPD. Eur Respir J 2010, 35(1):27-33.

42. Beran D, Yudkin JS: Looking beyond the issue of access to insulin: what is needed for proper diabetes care in resource poor settings. Diabetes Res Clin Pract 2010, 88(3):217-21.

43. Beran D, Yudkin JS, De Courten M: Access to care for patients with insulinrequiring diabetes in developing countries: case studies of Mozambique and Zambia. Diabetes Care 2005, 28(9):2136-40.

44. Chow CK, Teo KK, Rangarajan S, Islam S, Gupta R, Avezum A, Bahonar A, Chifamba J, Dagenais G, Diaz R, Kazmi K, Lanas F, Wei L, Lopez-Jaramillo P, Fanghong L, Ismail NH, Puoane T, Rosengren A, Szuba A, Temizhan A, Wielgosz A, Yusuf R, Yusufali A, McKee M, Liu L, Mony P, Yusuf S, PURE (Prospective Urban Rural Epidemiology) Study investigators: Prevalence, awareness, treatment, and control of hypertension in rural and urban communities in high-, middle-, and low-income countries. JAMA 2013, 310(9):959-68.

45. Gilmore $A B$ : Understanding the vector in order to plan effective tobacco control policies: an analysis of contemporary tobacco industry materials. Tob Control 2012, 21(2):119-26.

46. Stuckler D, McKee M, Ebrahim S, Basu S: Manufacturing epidemics: the role of global producers in increased consumption of unhealthy commodities including processed foods, alcohol, and tobacco. PLOS Med 2012, 9(6):e1001235.

47. Gilmore $A B$, McKee M: Moving East: how the transnational tobacco industry gained entry to the emerging markets of the former Soviet Union-part I: establishing cigarette imports. Tob Control 2004, 13(2):143-50

48. US Senate: Gateway to Addiction: A Survey of Popular Electronic Cigarette Manufacturers and Targeted Marketing to Youth. Washington DC: US Senate; 2014.

49. Mandal S, Gilmore AB, Collin J, Weishaar H, Smith K, McKee M: Block, Amend, Delay: Tobacco Industry Efforts to Influence the European Union's Tobacco Products Directive (2001/37/EC). Brussels: Smoke Free Partnership; 2009.

50. Attaran A, Pang T, Whitworth J, Oxman A, McKee M: Healthy by law: the missed opportunity to use laws for public health. Lancet 2012, 379(9812):283-5.

51. Kickbusch I: Addressing the interface of the political and commercial determinants of health. Health Promot Int 2012, 27(4):427-8.

52. Ottersen OP, Dasgupta J, Blouin C, Buss P, Chongsuvivatwong V, Frenk J, Fukuda-Parr S, Gawanas BP, Giacaman R, Gyapong J, Leaning J, Marmot M, 
McNeill D, Mongella Gl, Moyo N, Møgedal S, Ntsaluba A, Ooms G, Bjertness E, Lie AL, Moon S, Roalkvam S, Sandberg Kl, Scheel IB: The political origins of health inequity: prospects for change. Lancet 2014, 383(9917):630-67.

53. Bloom DE, Cafiero ET, Jané-Llopis E, Abrahams-Gessel S, Bloom LR, Fathima S, Feigl AB, Gaziano T, Mowafi M, Pandya A, Prettner K, Rosenberg L, Seligman B, Stein AZ, Weinstein C: The Global Economic Burden of Noncommunicable Diseases. Geneva: World Economic Forum; 2011.

54. Howell L: Global risks 2013. 8th edition. Geneva: World Economic Forum; 2013.

55. Vega J: Universal health coverage: the post-2015 development agenda. Lancet 2013, 381(9862):179-80.

56. UN General Assembly: Adopting Consensus text, General Assembly Encourages Member States to Plan, Pursue Transition of National Health Care Systems towards Universal Coverage. GA/11326. 2012. New York: United Nations; 2012.

57. World Health Organization: Sustainable Health Financing, Universal Coverage and Social Health Insurance. World Health Assembly Resolution 58.33. Geneva: WHO; 2005.

58. Haines A, Alleyne G, Kickbusch I, Dora C: From the Earth Summit to Rio + 20: integration of health and sustainable development. Lancet 2012, 378:2189-2197.

59. Dora C, Fletcher E, Adair-Rohani H, Alabaster G, Hossain R, de Onis M, Branca F, Neira M: Indicators linking health and sustainability in the post-2015 development agenda. Lancet, 2014

60. Horton R: Offline: why the sustainable development goals will fail. Lancet 2014, 393:2196.

61. Miranda JJ, Wells JC, Smeeth L: Transitions in context: findings related to rural-to-urban migration and chronic non-communicable diseases in Peru. Rev Peru Med Exp Salud Publica 2012, 29(3):366-72.

62. Prentice AM: Early influences on human energy regulation: thrifty genotypes and thrifty phenotypes. Physiol Behav 2005, 86(5):640-5

63. UN Committee on Economic Social and Cultural Rights: General Comment No. 14: The Right to the Highest Attainable Standard of Health. E/C.12/2000/4 New York: United Nations; 2000.

64. Open Working Group, Introduction to the proposal of the Open Working Group for Sustainable Development Goals. http://sustainabledevelopment.un. org/focussdgs.html, 2014

doi:10.1186/s12992-014-0074-8

Cite this article as: McKee et al:: Towards a comprehensive global approach to prevention and control of NCDs. Globalization and Health 2014 10:74

\section{Submit your next manuscript to BioMed Central and take full advantage of:}

- Convenient online submission

- Thorough peer review

- No space constraints or color figure charges

- Immediate publication on acceptance

- Inclusion in PubMed, CAS, Scopus and Google Scholar

- Research which is freely available for redistribution 